\title{
Inversion of soil moisture by wavelet analysis and multi-star fusion
}

\author{
Zhigang ZHANG ${ }^{1}$,Chao REN ${ }^{1,2}$, Yueji LIANG ${ }^{1,2}$,Yalong PAN ${ }^{1}$, Yibang HUANG ${ }^{1}$, Lv ZHOU ${ }^{1,2}$ \\ 1. College of Geomatics and Geoinformation, Guilin University of Technology, Guilin 541004, China \\ 2. Guangxi Key Laboratory of Spatial Information and Geomatics, Guilin 541004, China
}

KEY WORDS: GPS-IR; Soil Moisture; Wavelet analysis; Multi-star fusion

\begin{abstract}
:
Soil moisture content is an important parameter in hydrology, meteorology and agriculture, and it is of great significance for meteorological forecast, flood disaster and water resource cycle. Global Positioning System Interferometric Reflectometry (GPS-IR) is a new remote sensing technique with low cost, high efficiency and high resolution.. Using GPS-IR to invert soil moisture, snow depth, sea level and other aspects compared with traditional measurements, greatly reducing the difficulty of measurement and improving the accuracy of estimation. In view of how to efficiently and accurately separate satellite reflection signals and invert soil moisture, this paper considers the time-rate characteristics of wavelet analysis and the advantages of multi-star fusion. This paper proposes a combination of wavelet analysis and multi-star fusion estimation model for the existing research and analysis. First, the GPS satellite straight and reflected signals are separated by wavelet analysis, and then the relative delay phase is obtained by the sine fitting model. The multi-satellite relative delay phase is effectively analyzed and selected by a linear regression model. Finally, the change in soil moisture is estimated by establishing a multi-star fusion model. The feasibility and effectiveness of using wavelet analysis and multiple GPS satellites to estimate soil moisture were compared and analyzed.

Take the monitoring data provided by the PBO of the US Sector Boundary Observation Program as an example. Comparative analysis of the feasibility and effectiveness of soil moisture estimation using single or multiple GPS satellites.The results of the two data show that the linear regression equation can better describe the relationship between relative delay phase and soil moisture.Wavelet analysis fully exploits the performance of the identification trend term in the process of satellite reflection signal separation.Using a single satellite for soil moisture inversion, it is difficult to accurately grasp the variation law of soil moisture, and the error of inversion error fluctuates greatly, which is prone to jump phenomenon.Multiple satellites can effectively combine the advantages of each satellite and effectively suppress abnormal jumps.

The method of this paper gives full play to the advantages of multiple linear regression models.This model effectively suppresses the transition phenomenon. It combines wavelet analysis and multi-star fusion to effectively suppress abnormal jump values. The estimation error is stable and the inversion accuracy is improved, which provides soil moisture monitoring. An accurate and efficient method.This not only ensures the stability of local errors during the separation of satellite reflected signals, but also effectively suppresses abnormal jumps when estimating a single satellite. A single satellite does not easily affect the inversion process. Therefore, soil moisture estimation can be feasible and effective as a linear event estimate.
\end{abstract}

\section{1 introduction}

Global Positioning System-Interference Reflection (GPS-IR) is a new type of remote sensing technology used in recent years for monitoring and forecasting soil moisture, snow depth and sea ice ${ }^{[1-3]}$. Soil moisture is not only an important indicator for assessing the cycling and change of water resources in the region, but also a necessary parameter in climate and agricultural environment research ${ }^{[4]}$. Monitoring soil moisture has important application value for meteorological changes, flood disasters and water resources cycle. Traditional methods for measuring soil moisture use hygrometer measurement, drying weighing method and neutron instrument method. These methods often require field operation, which is only suitable for small-scale monitoring, and cannot achieve continuous long-term monitoring in the area. Low efficiency and other shortcomings ${ }^{[3]}$. In recent years, the use of GPS-IR to monitor soil moisture has become a research hotspot with high efficiency, low cost and high precision. Rodriguez-Alvarez $\mathrm{N}$ et al. ${ }^{[5]}$ proposed IPT (Interference Patern Technique) soil moisture measurement technology using a special receiver and vertically polarized antenna; Min Minsi et al. [6] pointed out that SNR value can effectively track soil water content. Trend. Zavorotny et al. ${ }^{[7]}$ proved that using relative delay phase to invert soil moisture is more advantageous than amplitude and SNR value; Ren Chao et al. ${ }^{[8]}$ proposed a multi-star fusion inversion model of soil moisture, which solved the problem better. The phenomenon of abnormal jumping of a single satellite. Wu Jizhong et al. ${ }^{[9]}$ used a modified Lomb-Scargle spectrum to estimate the parameters of reflected signals, and obtained more accurate and reasonable reflected signal parameters. Based on the above research, the separation of satellite reflection signals often adopts a low-order polynomial fitting method, which is limited to the case where the SNR observation sequence changes are stable, but the SNR value itself is susceptible to various uncertainties in the space environment. It tends to exhibit nonlinear and non-stationary variations, so it is difficult to establish accurate separation models directly through low-order polynomials. According to the characteristics of SNR value change, combined with the excellent characteristics of wavelet analysis in the trend recognition of nonlinear signals, the selection of 
wavelet basis functions and the number of decomposition layers in wavelet analysis are considered. Therefore, this paper proposes a separation model based on wavelet analysis, focusing on its influence on the accuracy of the reflected signal of the separated satellite, and through multi-star fusion to optimize the soil moisture inversioneffect.

\section{Principle and method}

\subsection{Principle of satellite reflection signal}

The core data of GPS-IR remote sensing technology is the SNR observation. The multipath effect is that the receiver simultaneously receives theGPS signal and the satellite signal reflected by the station and the satellite direct signal. These two

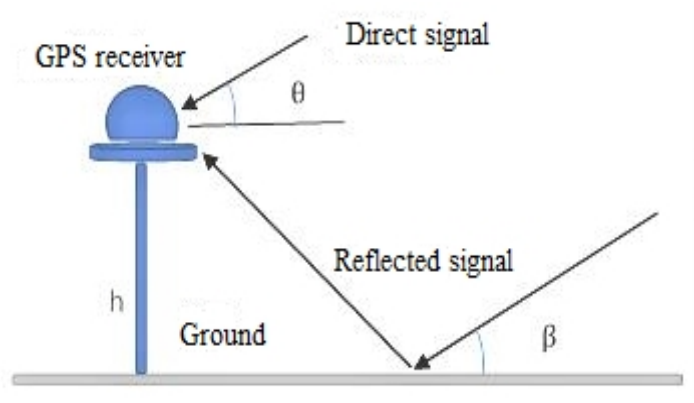

(a) Multipath effect signals are superimposed on each other to cause the observation value and the true value. There is a certain deviation. The SNR value is mainly affected by the multipath effect, and the SNR can be described as ${ }^{[10]}$ :

$$
S N R=S_{d}+S_{m}
$$

In the formula, $S_{d}$ represents a direct satellite signals, $S_{m}$ represents a satellite reflected signal. Therefore, the signal of the GPS receiver is often a superposition of the satellite straight and reflected signals, as shown in Figure 1. It has been shown in the literature ${ }^{[11]}$ that GPS is more affected by multipath effects at low satellite elevation angles. The soil composition remains relatively constant in the limited reflection area around the station. Soil moisture information is often included in multipath effects, so separating satellite reflections from SNR values is especially critical.

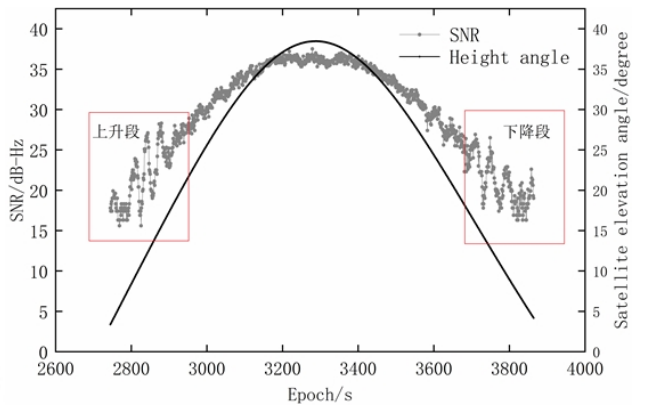

(b) PRN06 satellite observations of SNR

Fig.1 Multipath effect simulation and SNR observations

In Fig. 1(a), $h$ indicates that the antenna ishigh,

$\theta$ indicates the incident angle of the satellite, and

$\beta$ indicates the angle between the satellite signal and the ground. The direct and reflected signals received by the receiver are superimposed to obtain SNR observations. Figure 1(b) shows the SNR observations from the P02 station of the PBO, which was solved by TEQC on the 130th day of 2010. It can be seen that the multipath effect is particularly noticeable at low satellite elevation angles. Each satellite includes two phases of ascending and descending. It has been shown ${ }^{[12]}$ that the relationship between the surface reflection wavelength of the satellite signal and the surface is in accordance with the Fraunhofer criterion, and the reflection ellipse and its size are determined by the Fresnel reflection principle. Due to the space, only the satellite elevation angle of the 132nd day of the PRN06 satellite is given. A reflective area with a range of $5-20^{\circ}$ is shown in Figure 2. It can be seen that the left side is the sky satellite trajectory map. Within oneday, the satellite appeared twice ascending and descending, and the direction of each occurrence was different. The path of the reflection point was distributed in four directions, and the radiationradius of the reflected signal was up to about $45 \mathrm{~m}$.
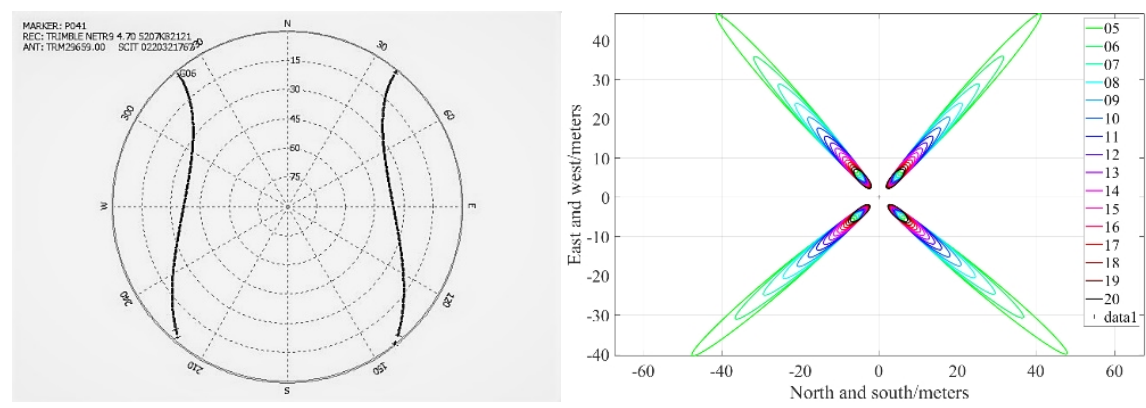

Fig.2 PRN06 satellite running track map and Fresnel reflection area

Under a single reflection condition, there is a linear relationship between the SNR reflected signal component and the sine (or cosine) of the incident angle of the satellite ${ }^{[13]}$ :

to the multiple linear regression model is to calculate the corresponding parameter matrix $B$. The least squares criterion is adopted, that is, the optimal parameter $\widehat{B}$ satisfies the minimum:

$$
S_{m}=A_{m} \cos \left(\frac{4 \pi h}{\lambda} \sin \theta+\varphi_{m}\right)
$$


Where, $A_{m}$ represents the amplitude of the satellite reflected signal, $\lambda$ represents the wavelength, and $\varphi_{m}$ represents the relative delay phase. Among them, $A_{m}$ and $\varphi_{m}$ are the parameters to be sought.

\subsection{Wavelet analysis principle}

Assume that the SNR ervation set $f(t)$ is:

$$
f(t)=\left[x_{1}^{0}, x_{2}^{0}, x_{3}^{0}, \ldots, x_{t}^{0}\right],(t=1,2,3 \ldots)
$$

In the formula, $t$ represents the number of epochs.

Wavelet analysis gradually multi-scale refines the original signal by wavelet-based function stretching and translation operation ${ }^{[14-15]}$. The wavelet basis function is obtained by scaling and translating a set of finite-length decaying mother wavelets. When the wavelet is used for multi-layer decomposition, the separated low-frequency signal has better stability and smoothing performance, and can show the trend of the signal. Decompose using wavelets to:

$$
W f(a, b)=\int f \cdot \varphi(a, b)(t) d t
$$

In the formula, $a$ is a scale factor, $b$ is a translation factor, and $\varphi(a, b)(t)$ is a continuous wavelet generated by a wavelet function. Then use $W f(a, b)$ to reconstruct $f(t)$ as:

$$
f(t)=C_{\varphi}^{-1} \int_{-\infty}^{\infty} \int_{-\infty}^{\infty} \frac{W f(a, b)}{a^{2}} \varphi(a, b)(t) d a d b
$$

In the formula, $C_{\varphi}$ is a wavelet basis function. It can be seen that $f(t)$ is the low frequency component reconstructed by the signal in multiple layers. In this paper, the coif5 wavelet function is used to decompose and reconstruct the SNR signal.

\subsection{Multi-linear fusion principle of multiple linear}

\section{regression}

Multiple linear regression is the reaction of multiple factors to the same result. It is a method of statistical prediction ${ }^{[16]}$. Let the soil moisture be the reaction variable $Y$, the relative delay phase of the satellite is the explanatory variable $x$, and the observation of the $\mathrm{n}$ satellite samples $\left(x_{1}, x_{2}, \ldots x_{n}\right)$, the multiple linear regression model can be obtained as:

$$
Y=b_{0}+b_{1} x_{1}+b_{2} x_{2}+\ldots+b_{n} x_{n}+u
$$

Marked with a matrix:

$$
\left[\begin{array}{c}
y_{1} \\
y_{2} \\
\ldots \\
y_{n}
\end{array}\right]=\left[\begin{array}{lllll}
1 & x_{11} & x_{12} & \ldots & x_{1 n} \\
1 & x_{21} & x_{22} & \ldots & x_{2 n} \\
1 & \ldots & \ldots & \ldots & \ldots \\
1 & x_{k 1} & x_{k 2} & \ldots & x_{k n}
\end{array}\right]\left[\begin{array}{c}
b_{0} \\
b_{1} \\
b_{2} \\
\ldots \\
b_{n}
\end{array}\right]+\left[\begin{array}{c}
u_{1} \\
u_{2} \\
\ldots \\
u_{n}
\end{array}\right]
$$

The above formula can be abbreviated as: $Y=B X+U$. In the formula, $k$ represents the annual accumulation of days, $k=1,2 \ldots, i$. The key $\sum u_{n}^{2}=\sum\left(y_{n}-\left(\widehat{b_{0}}+\widehat{b_{1}} x_{1}+\widehat{b_{2}} x_{2}+\ldots+\widehat{b_{n}} x_{n}\right)\right)^{2}$.

Therefore, this method is used to determine the parameter $B$.

\section{3. experiment analysis}

This paper selects from the United States Plate Boundary Observatory Program (Plat Boundary Observatary, PBO) (http://xenon.colorado.edu/portal) P041 data monitoring stations provided by experiments. From the Google Earth multi-spectral image (space resolution of $2 \mathrm{~m}$ ) and (b) P041 station map in Figure 3(a), it can be seen that the field around the station is wide and the terrain is flat, and the vegetation is sparse, which is beneficial to the monitoring of soil moisture. . The station receiver model is TRIMBLE NERT9, adopts SCIT radome, and the antenna model is TRM59800.80, which can monitor high-quality SNR observations for a long time, and conduct research on soil moisture inversion very early. Representative.

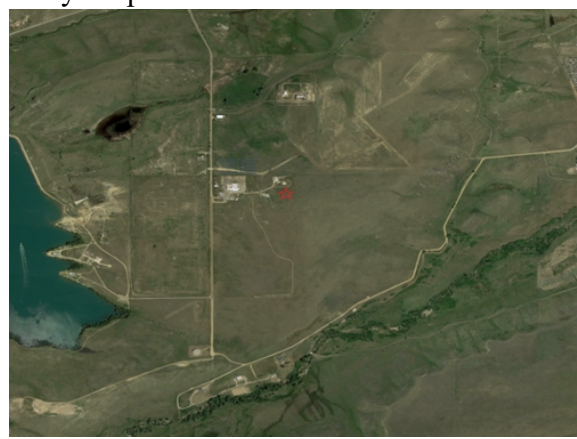

(a) Remote sensing image map

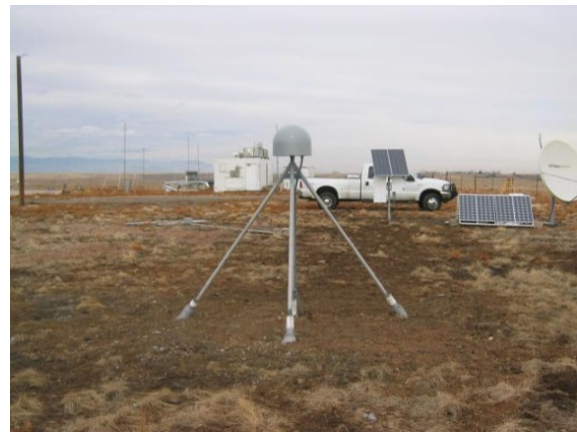

(b) P041 station

Fig.3 P041 station surrounding environmen

This experiment uses the station. This experiment uses the data from the 70th-300th day of the station in 2010. In order to compare the ability of the satellite to reflect the reflected signal and multi-star fusion of wavelet analysis, four schemes are set up. Scheme 1 uses a second-order polynomial to fit the satellite reflection signal and uses a single-star model to invert soil moisture; Scheme 2 uses a second-order polynomial and multi-star model inversion; Scheme 3 uses wavelet analysis and a single-star model for inversion; Inversion using wavelet analysis and multi-star models. First, the TEQC software is used to solve the GPS monitoring data to obtain the SNR observation (L2 carrier). A second order polynomial and wavelet analysis by separating the reflected satellite signal to space limitations, only given number PRN06 satellite separation results, as shown in FIG. A relative delay phase is obtained using a nonlinear least squares fit. Due to space limitations, this article only gives the 
results of some satellites from the 91 - 272 days solution, as shown in Figure 4.

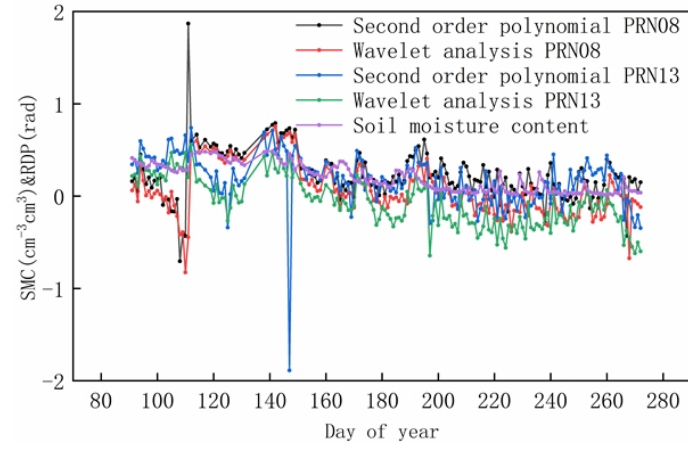

(a) The delayed phase relative PRN08,13

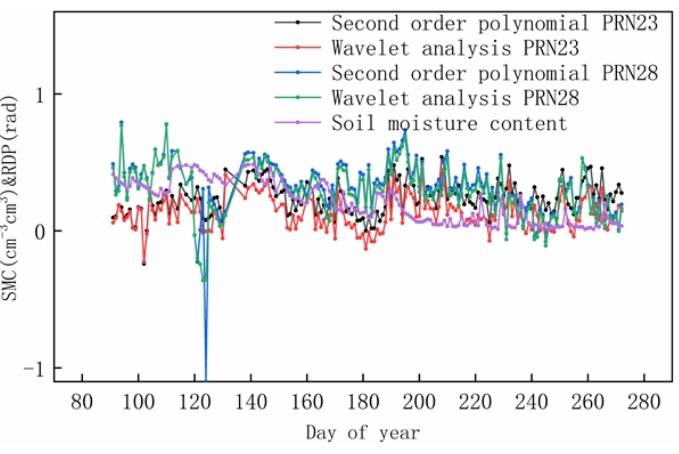

(b) The delayed phase relative PRN23,28

Fig.4 Relative delay phase

As can be seen from Figure 3, the relative delay phase can respond accordingly as the soil moisture changes. For 107-108, 146-147, and 124-125 days, the relative delay phase obtained by the second-order polynomial has a large abnormal jump, which causes the SNR time series trend to change due to the sharp rise of soil moisture, resulting in the method pole. The earth increases the error of the straight and reflected signals of the separated satellites. The linear regression equation coefficient $\mathrm{R}$ between the relative delay phase of the satellites of the station and the soil moisture is shown in Fig. 5 throughout the period. It can be seen that the overall accuracy of the inversion of the linear regression model established by the single star of the scheme 3 is higher than that of the scheme 1 . The $\mathrm{R}$ between the relative delay phases of different satellites and the soil moisture is inconsistent. This may be related to the performance of the satellite and the azimuth of the received signal. Further comparison found that the correlation coefficient $\mathrm{R}$ between the relative delay phase and soil moisture of a single satellite is generally low, which is mainly due to the fact that a single satellite easily causes abnormal jump values in the surface multipath environment during observation. Therefore, it is difficult to eliminate abnormal jump values directly by some method or manual correction, and it is not conducive to establishing a linear estimation model to invert soil moisture. Based on this, it is possible to establish a multivariate linear regression model to achieve soil moisture estimation through the fusion of multiple satellites to form a complement.

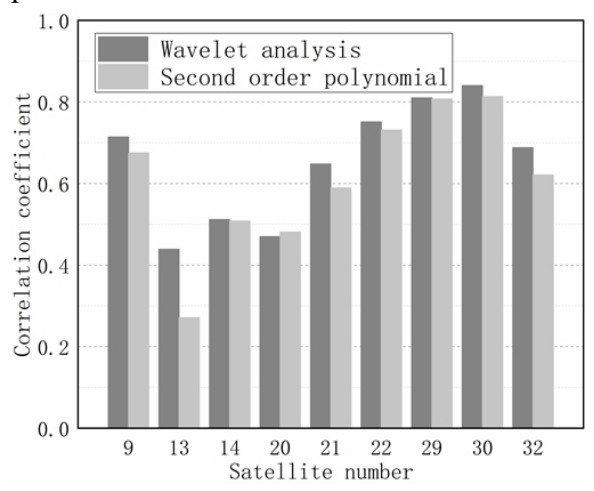

Fig.5 P041 station

In order to verify the feasibility and effectiveness of combining wavelet analysis and multi-star fusion, this paper screens out the threshold range of linear regression correlation coefficient $\mathrm{R}$ greater than 0.6. A multivariate linear regression soil moisture estimation model was established by selecting the relative delay phases of six satellites at the P041 station. Comparative analysis was performed by setting scheme 2 and scheme 4. For the P041 station, model 164-240 days was used as a sample, and then the multiple linear regression model was used to fuse multiple satellite data. The soil moisture product provided by the US Boundary Observation Program PBO is used as a reference value. Due to space limitations, only the linear relationship between the estimation results of the P041 station and the soil moisture is given, as shown in Fig. 6 .
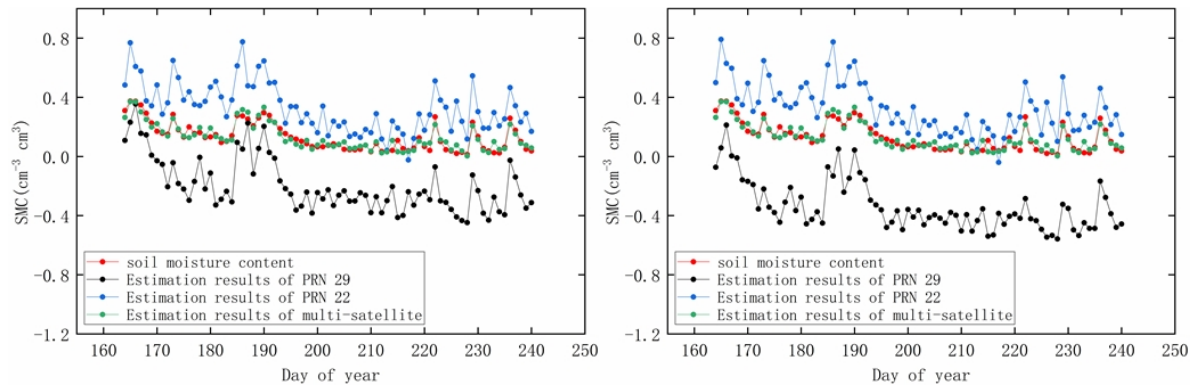

(a) PRN22, 29 scheme 2, 4 estimation results 

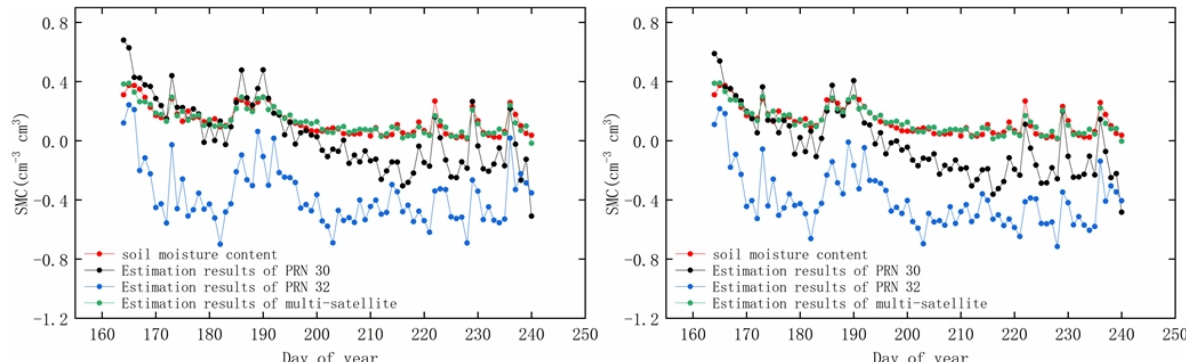

(b) PRN30, 32 scheme 2, 4 estimation results
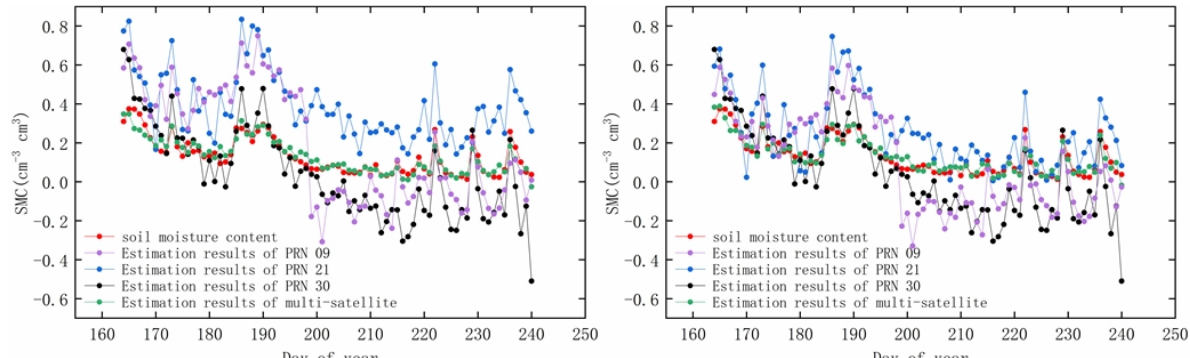

(c) PRN09、21、30 scheme 2, 4 estimation results
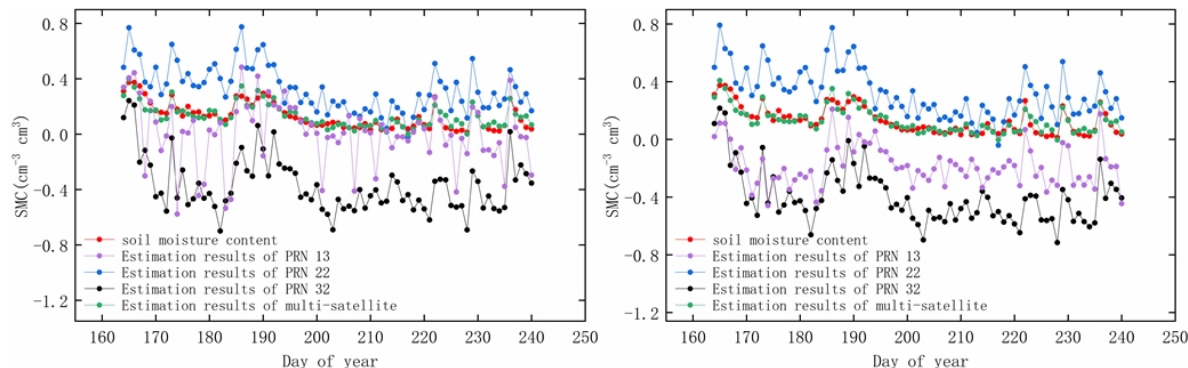

(d) PRN13、22、32 scheme 2, 4 estimation results
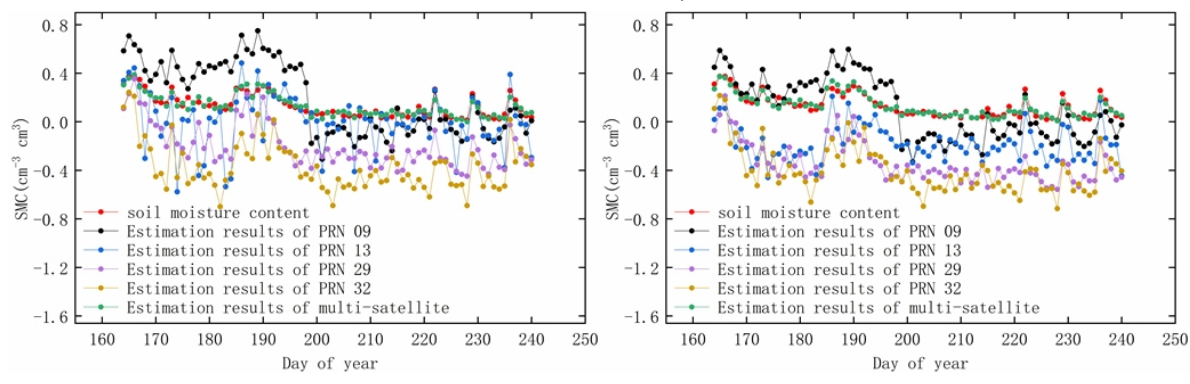

(e) PRN09、13、29、32 scheme 2, 4 estimation results
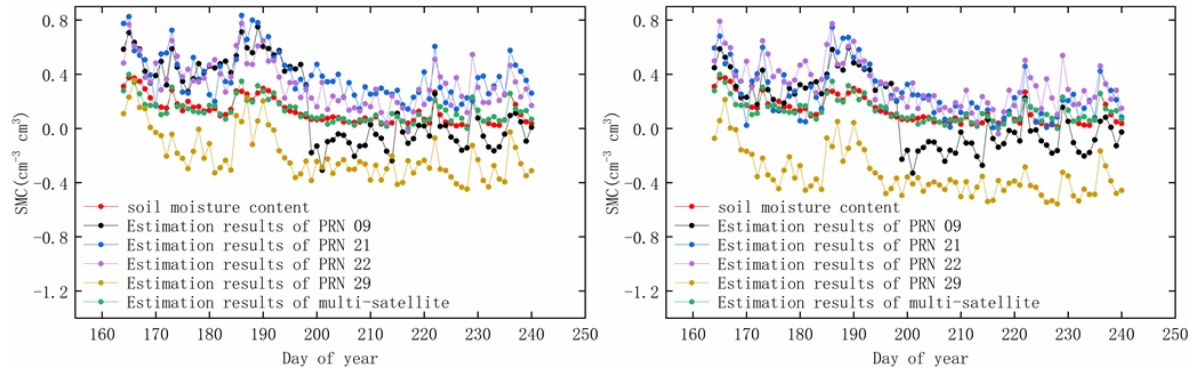

(f) PRN09、21、22、29 scheme 2, 4 estimation results

Fig.6 P041 station

It can be seen from Fig. 6 that it is difficult for a single satellite to accurately grasp the law of soil moisture change, and the estimation error is large. For the annual accumulation of soil moisture fluctuations, the estimation is prone to abnormal jumps, especially the low-order polynomial separation model. As a result of the estimation, in the band where the soil moisture fluctuation is small, the estimation results of moisture reflection information is disturbed. In further comparison, the multi-star fusion effectively suppresses the abnormal jump of some satellites, and can stably represent the fluctuation of soil moisture. It can be seen that multivariate linear fusion is more advantageous than single satellite estimation.

In order to further comprehensively evaluate the performance of each program, this paper uses $\mathrm{R}$ to 
some satellites are prone to distortion. For example, the PRN09 satellite is in the range of 190-200 days. The PRN29 and 32 satellites are very susceptible to signal fluctuations due to the traditional separation method. These are mainly due to the fact that a single satellite signal is received by the receiver at a different location in a multi-path surface environment. The difference in impact is large, so that useful soil assess. Due to space limitations, only some satellite estimation results are given, as shown in Figure 7. It can be seen that the response patterns of different satellites to soil moisture are different. Combined with Figure 7 and Table 1. The overall accuracy of schemes 2 and 4 is higher than that of schemes 1 and 3 . The overall accuracy of scheme 4 is higher than that of scheme 2 .
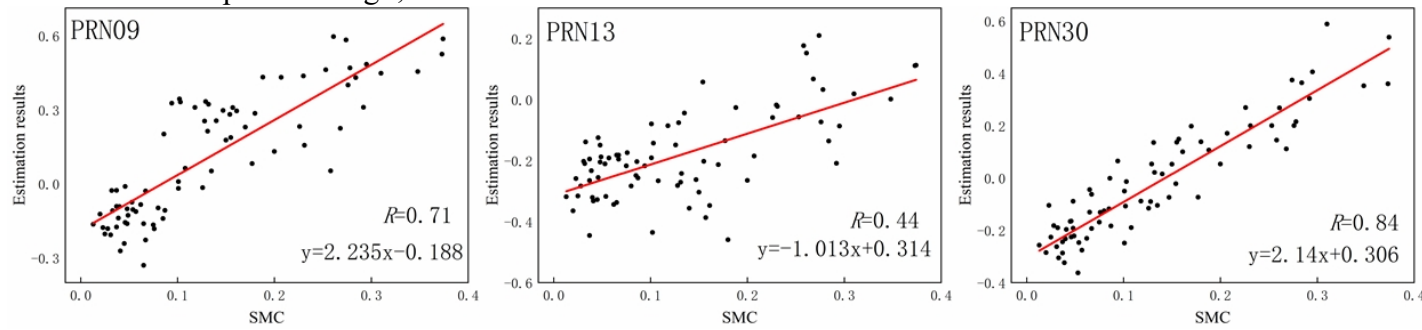

(a) Wavelet analysis single estimation linear correlation coefficient
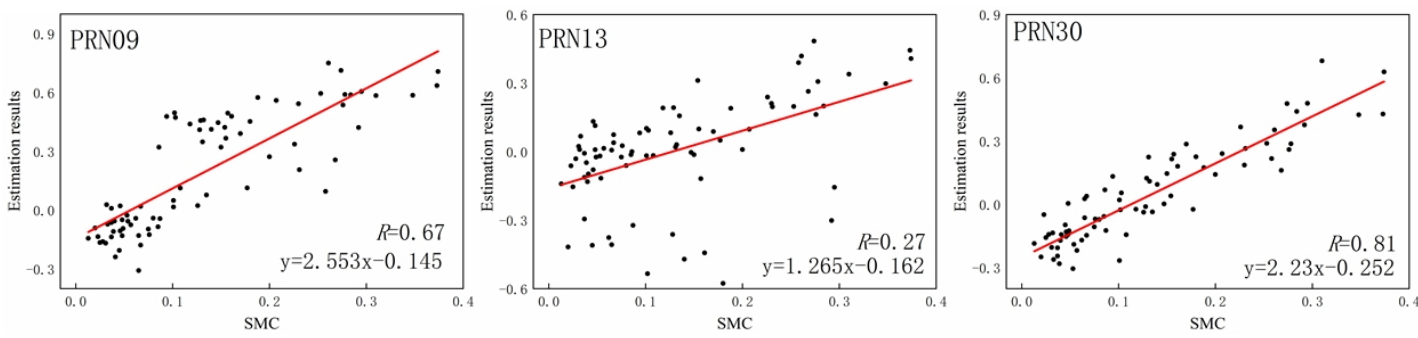

(b) Second-order polynomial single estimate linear correlation coefficient

Fig. 7 P041 station Schemes 1 and 3 to estimate the linear correlation coefficient

Table 1 Multi-star fusion estimation R comparison statistics

\begin{tabular}{ccccccc}
\hline P041 SAT & $\begin{array}{c}\text { PRN22、 } \\
29\end{array}$ & PRN30、32 & PRN9、21、30 & PRN13、22、 & PRN09、21、 & PRN09、13、 \\
& & & 32 & $22 、 29$ & $29 、 32$ \\
\hline $\begin{array}{c}\text { Second order } \\
\text { polynomial }\end{array}$ & 0.888 & 0.867 & 0.847 & 0.828 & 0.891 & 0.870 \\
Wavelet analysis & 0.891 & 0.876 & 0.875 & 0.856 & 0.900 & 0.881 \\
\hline
\end{tabular}

In summary, the multivariate linear regression model based on multi-satellite fusion fully integrates the performance of each satellite, so that the relative delay phases of each satellite form a complement; combined with wavelet analysis to separate satellite reflection signals greatly reduces the anomaly jump, the model Performance has also been better played. Moreover, multi-satellite fusion is more adaptable to soils with different humidity changes than single satellites, and is superior to direct inversion of satellites. However, the phase combination observation of multiple GPS satellites does not significantly improve the accuracy, which is due to the increase in the number of satellites to a certain number and the increase in spatial resolution to the critical point.

\section{Conclusion}

Long-term monitoring of soil moisture is of great significance to environmental science research. Combining wavelet analysis and multi-star fusion ideas, this paper establishes a separation satellite direct reflection signal model and multiple linear regression models, and draws the following conclusions:

(1) During the observation process, the azimuths of different satellites are different with respect to the station, and there are certain differences in the response mode to soil moisture. At low satellite elevation angles, the reflected signal radiation range can reach about $45 \mathrm{~m}$. There is a certain linear correlation between relative delay phase and soil moisture.

(2) Wavelet analysis Separation of satellite direct reflection signals can obtain accurate satellite reflection signals, effectively reducing the impact of abnormal hopping values during data processing.

(3) Combining wavelet analysis and multi-star fusion to estimate soil moisture, multi-star fusion is not susceptible to single-star relative delay phase changes, and effectively integrates different satellites to form complementary. It can greatly improve the accuracy of inversion and is superior to the accuracy of traditional method inversion. The next step is to conduct in-depth research on wavelet multi-scale different components and multi-system fusion.

\section{REFERENCES}

[1] Zhang S. C., Dai K. Y., Nan Y., Zhang Q., 
Zhai W., Li Z. Y., Zhao Y. H., 2018. GNSS-MR technology for preliminary study of snow depth $d$ etection. Journal of Wuhan University: Information Science Edition. Geomatics and Information Scien ce of Wuhan University. 43(2), 234-240. doi.org/1 0.13203/j.whugis20150236. (张双成, 戴凯阳, 南阳, 张 勤, 䨉伟, 李振宇, 赵迎辉.GNSS-MR技术用于雪深探 测的初步研究[J]. 武汉大学学报(信息科学版), 201 8, 43(02):234-240. doi.org/10.13203/j.whugis201502 36.)

[2] Larson, K. M., Braun, J. J., Small, E. E., Zavorotny, V. U., Gutmann, E. D., Bilich, A. L., 2010. GPS multipath and its relation to near-surface soil moisture content. IEEE Journal of Selected Topics in Applied Earth Observations and Remote Sensing. 3(1), 91-99. doi.org/10.1109/jstars.2009.2033612.

[3] Zhang Y., Meng W. T., Gu Q. M., Han Y. L., Chao Y. C., Xia Q., Wang W., 2014. Bohai Sea Ice Experiment Based on GPS Reflected Sign al Technology. Acta Oceanologica Sinica. 36(11), 64-73. doi.org/10.3969/j.issn.0253-4193.2014.11.008.( 张云, 孟婉婷, 顾祈明, 韩彦岭, 曹云昌, 夏青, 王炜.基于 GPS反射信号技术的渤海海冰实验 $[\mathrm{J}]$. 海洋学报(中 文版)，2014，36(11):64-73. doi.org/10.3969/j.issn.02 53-4193.2014.11.008.)

[4] Jin S. G., Zhang Q. Y., Qian X. D., 2017. T he latest progress and application prospects of GN SS reflection measurement (GNSS+R). Acta Geod aetica et Cartographica Sinica. 46(10), 1389-1398. doi.org/CNKI:SUN:CHXB.0.2017-10-023. (金双根, 张勤耘, 钱晓东. 全球导航卫星系统反射测量(GNSS+ R)最新进展与应用前景 $[\mathrm{J}]$. 测绘学报, 2017, 46(10): 1389-1398. doi.org/CNKI:SUN:CHXB.0.2017-10-02 3.)

[5] Rodriguez-Alvarez, N., Bosch-Lluis, X., Camp s, A., Vall-Llossera, M., Valencia, E., Marchan-H ernandez, J. F., Ramos-Perez I., 2009. Soil moistu re retrieval using GNSS-R techniques, experimenta 1 results over a bare soil field. IEEE Transactions on Geoscience and Remote Sensing. 47(11), 36163624. doi.org/10.1109/IGARSS.2008.4778973.

[6] Ao M. S., Zhu J. J., Hu Y. J., Zeng Y., Liu Y. D., 2015. GPS soil moisture monitoring using SNR observations. Geomatics and Information Sci ence of Wuhan University. 40(01), 117-120+127. doi.org/10.13203/j.whugis20130170. (敖敏思, 朱建 军, 胡友健, 曾云, 刘亚东. 利用SNR观测值进行GPS 土 壤湿度监测 $[J]$. 武汉大学学报(信息科学版), 2015,40 (01):117-120+127. doi.org/10.13203/j.whugis201301 70.)

[7] Zavorotny, V. U., Larson, K. M., Braun, J. J., Small, E. E., Gutmann, E. D., Bilich, A. L., 2010. A physical model for GPS multipath caused by land reflections, Toward bare soil moisture retrievals. IEEE Journal of Selected Topics in Applied Earth Observations and Remote Sensing. 3, 100-110. doi.org/ 10.1109/jstars.2009.2033608.

[8] Ren, C., Liang, Y. J., Lu, X. J., Yan, H. B., 2018. Research on the soil moisture sliding estimation method using the LS-SVM based on multi-satellite fusion. International Journal of Remote Sensing. 1-16. doi.org/ 10.1080/01431161.2018.1475778.

[9] Wu J. Z., Wang T., Wu W., 2018. Inversion model for monitoring soil water content using GP S-IR. Geomatics and Information Science of Wuha $n$ University. 43(06), 887-892. doi.org/10.13203/j.w hugis20160088. (吴继忠,王天, 吴玮.利用GPS-IR监 测土壤含水量的反演模型[J]. 武汉大学学报(信息科 学版),2018, 43(06):887-892. doi.org/10.13203/j.whu gis20160088.)

[10] Peng X. F., Wan W., Li F., Chen X. W., 2017. Suitability Analysis of GNSS-R Soil Moisture Remote Sensing. Journal of Remote Sensing. 21(03), 341-350. doi.org/10.11834/jrs.20176198. (彭学峰,万玮,李飞,陈 秀万.GNSS-R土壤水分遥感的适宜性分析 [J]. 遥感 学 报 , 2017, 21(03):341-350. doi.org/ 10.11834/jrs.20176198.)

[11] Ao M. S., Zhu J. J., Hu Y. J., Ye X. F., 2 018. Retrieving soil moisture using window GPS multipath interference phase. Geomatics and Infor mation Science of Wuhan University. 43(09), 1328 $-1332+1341$ d doi.org/10.13203/j. whugis20160246. (敖敏思,朱建军,胡友健, 叶险峰.利用窗口GPS多径 干涉相位反演土壤湿度 $[\mathrm{J}]$. 武汉大学学报(信息科学 版)，2018，43(09):1328-1332+1341. doi.org/10.1320 3/j.whugis20160246.)

[12] Chew, C. C., Small, E. E., Larson, K. M., Z avorotny, V. U., 2015. Vegetation sensing using GPS-interferometric reflectometry, Theoretical effec ts of canopy parameters on signal-to-noise ratio d ata. IEEE Transactions on Geoscience and Remot e Sensing. 53, 2755-2764. doi.org/10.1109/tgrs.201 4.2364513 .

[13] Chew, C., Shah, R., Zuffada, C., Hajj, G., Masters, D., Mannucci, A. J., 2016. Demonstratin $\mathrm{g}$ soil moisture remote sensing with observations $f$ rom the UK TechDemoSat-1 satellitemission. Geo physical Research Letters. 43(7), 3317-3324. doi.o rg/ 10.1002/2016GL068189.

[14] Wen L., Liu Z. S., Ge Y. J., 2002. Several methods of wavelet denoising. Journal of Hefei $U$ niversity of Technology(Natural Science). (02), 167 -172 .

doi.org/10.3969/j.issn.1003-5060.2002.02.002.(文莉， 刘正士,葛运建.小波去噪的几种方法 [J]. 合肥工业 大学学报(自然科学版), 2002(02):167-172. doi.org/1 0.3969/j.issn.1003-5060.2002.02.002.)

[15] Hou Z. Z., Yang W. C., 1997. Wavelet Tran sform and Multiscale Analysis of Gravity Anomali es in China. Chinese Journal of Geophysics. (01), 85-95. (侯遵泽,杨文采.中国重力异常的小波变换 与多尺度分析 [J]. 地球物理学报, 1997(01):85-95.)

[16] Wang H. W., Meng J., 2007. Predictive mod eling method for multiple linear regression. Journ al of Beijing University of Aeronautics and Astron autics. (04), 500-504. doi.org/10.3969/j.issn.1001-5 965.2007.04.028. (王惠文,孟洁.多元线性回归的预 测建模方法 [J]. 北京航空航天大学学报, 2007(04): 500-504. doi.org/10.3969/j.issn.1001-5965.2007.04.0 28.) 